\title{
Biomarker discovery in neurological diseases: a metabolomic approach
}

This article was published in the following Dove Press journal:

Open Access Journal of Clinical Trials

30 November 2009

Number of times this article has been viewed

\section{Afaf El-Ansary \\ Nouf Al-Afaleg \\ Yousra Al-Yafaee \\ Biochemistry Department, Science College, King Saud University, Riyadh, Saudi Arabia}

\begin{abstract}
Biomarkers are pharmacological and physiological measurements or specific biochemicals in the body that have a particular molecular feature that makes them useful for measuring the progress of disease or the effects of treatment. Due to the complexity of neurological disorders, it is very difficult to have perfect markers. Brain diseases require plenty of markers to reflect the metabolic impairment of different brain cells. The recent introduction of the metabolomic approach helps the study of neurological diseases based on profiling a multitude of biochemical components related to brain metabolism. This review is a trial to elucidate the possibility to use this approach to identify plasma metabolic markers related to neurological disorders. Previous trials using different metabolomic analyses including nuclear magnetic resonance spectroscopy, gas chromatography combined with mass spectrometry, liquid chromatography combined with mass spectrometry, and capillary electrophoresis will be traced.
\end{abstract}

Keywords: metabolic biomarkers, neurological disorders. metabolome, nuclear magnetic resonance, mass spectrometry, chromatography

\section{Introduction}

Ultimately, the main goals of research on human diseases are to cure the disorders or to increase the length and quality of life of those affected. Novel biomarker identification in neurological disorders will facilitate the achievement of these goals. First, by providing sensitive and selective clinical correlates for the evaluation and diagnosis of those affected by neurological disorders. Second, by providing insights into disease mechanisms that can be used to identify therapeutic targets and to develop efficacious compounds to target them.

Biomarkers that will be useful for either disease prediction or treatment should have one or more of several properties, including: (i) specific and selective association with illness in a population; (ii) heritability; (iii) state independence and presence, whether or not the clinical phenotype of the disease is present; (iv) co-segregation with disease within families; and (v) presence in relatives of affected individuals at a higher rate than in the general population. ${ }^{1,2}$

Accordingly, biomarkers have been classified as antecedent biomarkers (identifying the risk of developing an illness), screening biomarkers (screening for subclinical disease), diagnostic biomarkers (recognizing overt disease), staging biomarkers (categorizing disease severity), or prognostic biomarkers (predicting future disease course, including recurrence and response to therapy, and monitoring
Correspondence: A El-Ansary Biochemistry Department, Science College, King Saud University, PO Box 22452, Riyadh I I495, Saudi Arabia Email elansary@ksu.edu.sa 
efficacy of therapy). ${ }^{3-5}$ A naïve expectation is that single biomarkers can capture the complex process underlying an illness. Rather, by looking as perturbations of biochemical networks (systems view), it becomes clear that a multiparameter analysis (panel of markers or multiple metabolites) may provide better insight into disease diagnosis, prognosis, and treatment. ${ }^{5}$ By surveying for global changes in metabolic pathways, metabolomics-based approaches are more likely to provide a wealth of information that may be difficult to capture by looking at only one pathway or one biomarker.

The metabolome is the collection of small molecules that are found within a system which basically covers a broad range of small molecules such as glucose, cholesterol, adenosine-5' -triphosphate, biogenic amine neurotransmitters, lipid-signaling molecules, among many other classes of compounds. ${ }^{6}$ The identities, concentrations, and fluxes of metabolites are the final product of interactions between gene expression, protein expression, and the cellular environment (Figure 1). Thus, metabolomic information complements data obtained from other fields such as genomics, transcriptomics, and proteomics and adds a final piece to a systematic approach to the study of disease pathophysiology, identification of biomarkers and drug action $^{7-11}$ (Figure 1).

\section{Biochemical markers in neurological diseases}

Because of the inherent difficulties in characterizing and accessing neurological disorders, biomarkers that satisfy these criteria have been difficult to identify. For the purposes of developing disease diagnostics, peripheral tissues such as blood, urine and saliva are easily attainable ante-mortem. However, for discovering etiologically relevant genes, proteins, or small molecules, the preferred biological source is often those pathologically affected tissues that are more difficult to attain. Many attempts at bypassing the problem of tissue availability have used in vitro and animal models of neurological disease. However, given the complexities of human neurological disorders, which often contain significant behavioral components, these models are often imperfect. ${ }^{12}$

In many cases, the complexity of the brain itself presents a severe roadblock to identification of useful biomarkers. In most organs (eg, liver, muscle), cells are more homogenous in their phenotypes, transcriptomes, proteomes, and cellular interactions. However, in the brain, transcriptomes,

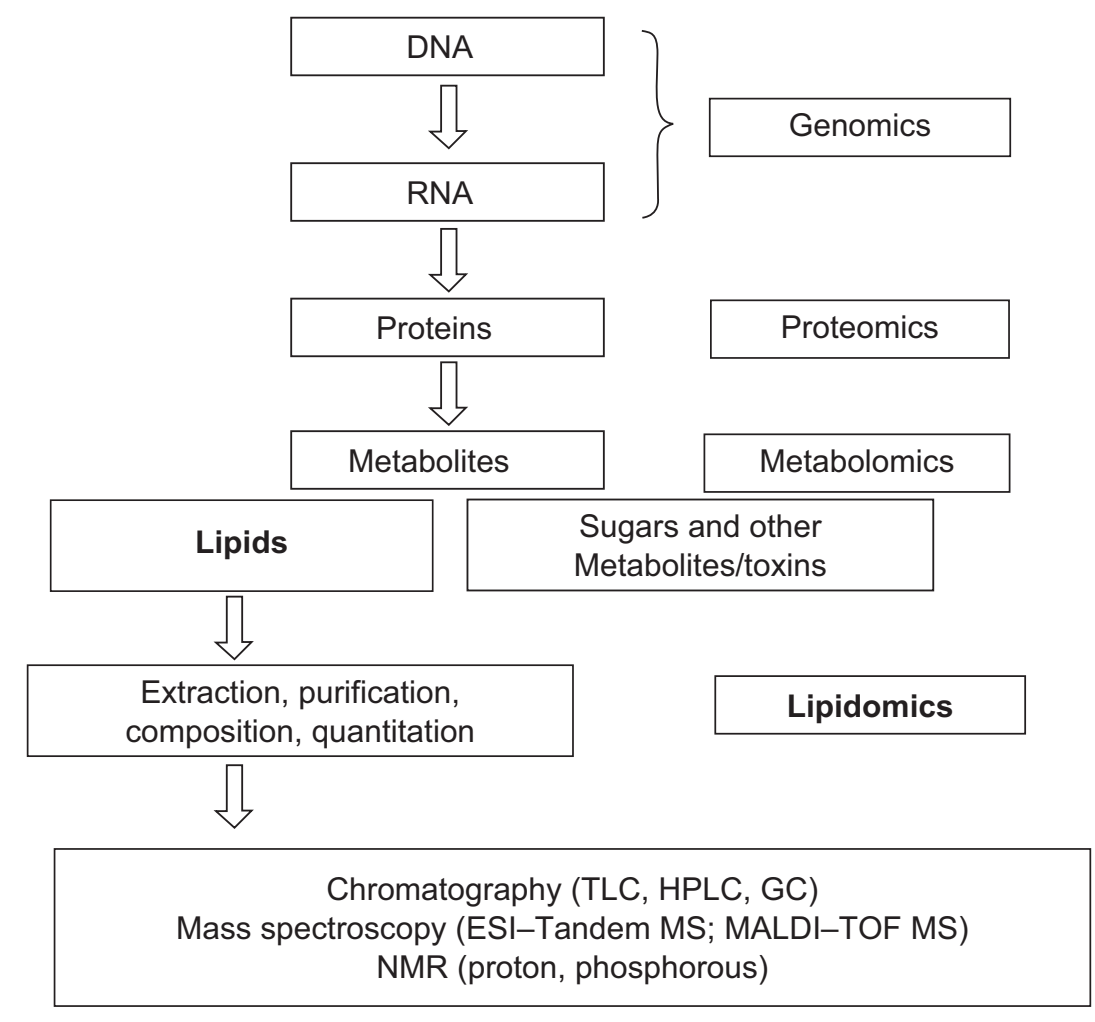

Figure I Metabolomic platform showing flow of information from DNA to proteins and finally to metabolites.

Abbreviations: ESI-Tandem MS, electrospray ionization-Tandem mass spectrometry; GC, gas chromatography; HPLC, high-pressure liquid chromatography; MALDI-TOF MS, matrix-assisted layer desorption/ionization-time-of-flight mass spectrometry; NMR, nuclear magnetic resonance; TLC, thin layer chromatography. 
proteomes, morphological phenotypes, and interactive connections vary widely within the neurons and glia.

According to the type of information that they provide, biomarkers for neurological disorders can also be classified as genetic, neuroimaging, clinical, or biochemical markers. ${ }^{13}$ Classical research (pre-metabolomics) on the identification of biochemical biomarkers in blood and cerebrospinal fluid (CSF) for neurological disorders has been aimed at assaying single metabolites. Often this search has been based on research hypotheses. Unfortunately, none of the single biomarkers identified to date have the desired sensitivity and specificity for diagnosis or have sufficient power to identify disorders at an early stage. Figure 2 demonstrates the possible mechanism related to brain injury together with the related metabolites.

Metabolomics is a functional approach for describing the modification associated with a given manipulation (eg, gene modification, toxicological insult, disease) in terms of changes in the global profile of metabolism of a cell, tissue or organism. Metabolomic techniques have been used to identify perturbations in biochemical pathways associated with diseases either in biological fluids (plasma, urine and cerebrospinal fluid), animal models (eg, yeast, mouse and sheep) and tissues or cell cultures.

The rationale for the use metabolomic approaches in the study of central nervous system (CNS) disorders aiming to capture more global biochemical disturbances and using this information for the identification of biomarkers that reflect. ${ }^{14-16}$ Studies have used CSF or blood (plasma or serum) to conduct biochemical analysis.

This review is a trial to elucidate the progress in using metabolomics for the early detection of metabolic biomarkers related to neurological disorders. We reviewed the current state of knowledge on plasma and serum biomarkers for neurodegenerative disorders with special emphasis placed on plasma biomarkers related to human

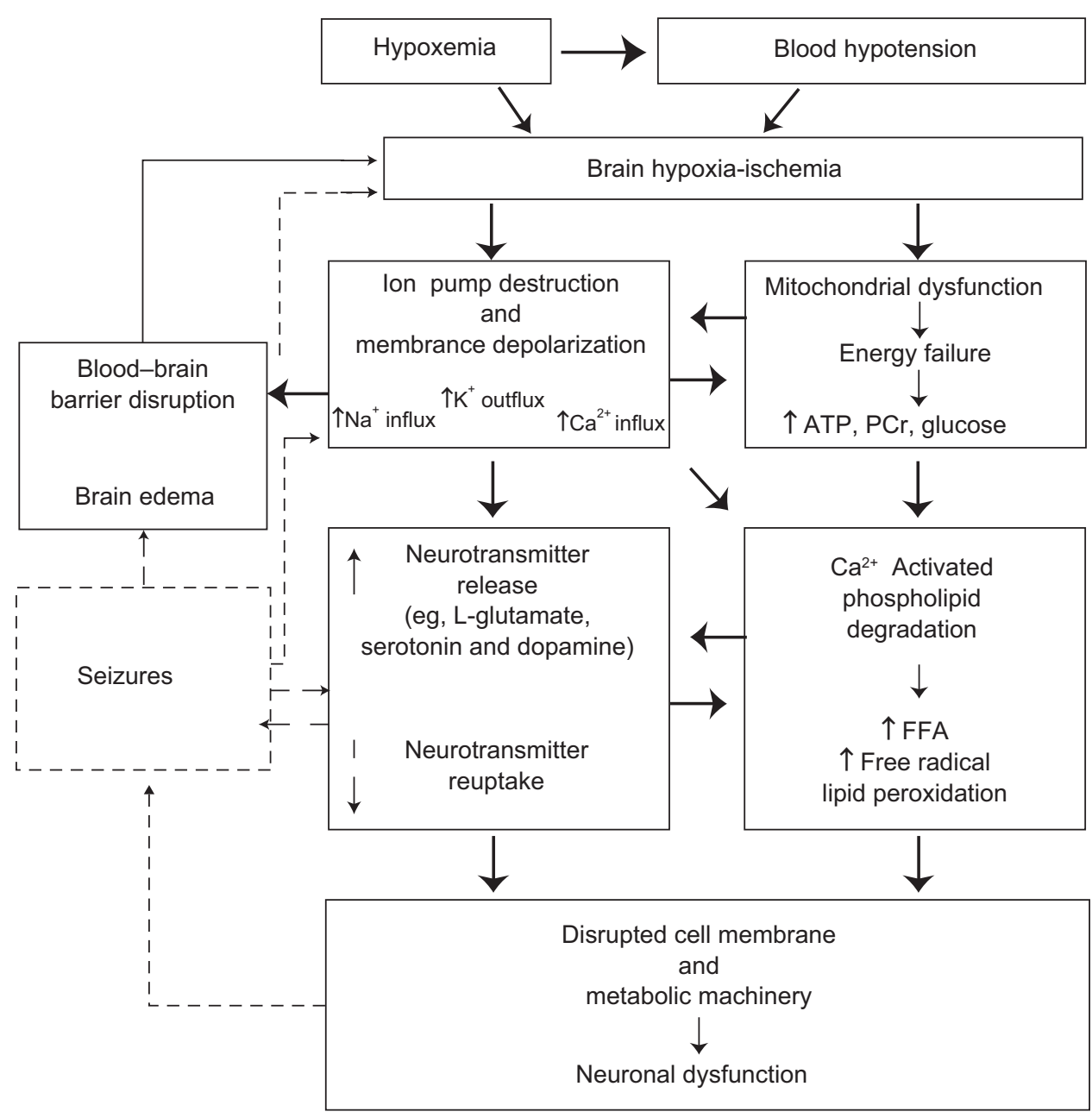

Figure 2 Possible mechanisms of brain metabolic machinery disturbances and related brain metabolites. Abbreviations: ATP, adenosine triphosphate; FFA, free fatty acid; PCr, phosphocreatine. 
metabolism research. With the keywords, 'neurodegenerative diseases' and 'plasma', we searched the following electronic databases: PubMed, Medline, and PsycINFO. We sorted articles by different research fields and core biomarkers using the terms 'metabolomics', 'amyloid beta', 'oxidative stress', 'inflammation', 'homocysteine', 'cholesterol', and 'lipoprotein'. Studies were also searched through crossreferences from published reviews and original papers.

\section{Standardization of metabolomics}

The metabolomic profile of a biological sample is affected by several physiological factors, including age, sex, diet, and circadian variations (Figure 1), and the related changes in human metabolic profiles have been investigated. ${ }^{17,18}$ As an example, a study conducted on healthy subjects adopting a strict diet and particular lifestyle showed a relatively small intersubject and intrasubject variability. ${ }^{19}$ Another study in which no dietary restrictions were applied found a significant degree of inter-individual variability in urinary metabolomic profile. ${ }^{20}$ This variability is reduced if a standard diet is followed on the day before urine collection. ${ }^{21}$ In metabolomics, more than in the other "-omic" sciences, it is therefore crucially important to collect background data on the individual concerned to help interpret the results. In addition, for metabolomic experiments, it is important to develop standard protocols regarding sample collection and storage, chemical analyses, data processing, and the exchange of information. ${ }^{22}$ The Metabolomics Standard Initiative (MSI) was created, with the support of the Metabolomic Society (www. metabolomicssociety.org), to recommend standard protocols for use in all aspects of metabolomic research. ${ }^{23}$ Such standardization will facilitate the future development of applications of the metabolomic approach.

\section{Brain metabolites, location, and significance}

Magnetic resonance spectroscopy (MRS) has been shown to be an effective noninvasive diagnostic tool that can be used to monitor serially biochemical and metabolic changes in serial disease processes that affect the brain. Major brain metabolites detected with MRS are N-acetyl aspartate (NAA), choline (Cho), creatine $(\mathrm{Cr})$, lactate, myoinositol, glutamine and glutamate combinations, and lipids. Other resonances observed in specific settings have included alanine, cytosolic and noncytosolic amino acids, scylloinositol, acetoacetate, acetone, and ethanol.

\section{$\mathrm{N}$-acetyle aspartyl glutamate and $\mathrm{N}$-acetylaspartate}

N-acetyl aspartyl glutamate (NAAG), a putative neurotransmitter or neuromodulator and NAA are accepted as neuronal markers. ${ }^{24}$ As such, their concentrations will decrease with many insults to the brain. ${ }^{25} \mathrm{~A}$ decrease in NAA has been shown in infants relative to adults; with senescence; ${ }^{26}$ in many diseases including neoplasm, hypoxia, ischemia, epilepsy, and so forth. Glutamate and N-acetylaspartateglutamate are colocalized with NAA in neurons. NAA is synthesized from L-aspartate and acetyl-co-enzyme A by L-aspartate $\mathrm{N}$-acetyl transferase, an enzyme localized to the brain, and also through cleavage of NAAG. Breakdown of NAAG releases both NAA and glutamate, and subsequent breakdown of NAA leads to aspartate. These compounds are excitatory amino acids and are increased with ischemia. It is possible that concentrations of NAAG and glutamate may serve to monitor treatments assigned to protect brain tissues by blocking excitatory amino acids. NAA is not present in tumors outside the central nervous system. A congenital error in NAA metabolism has been associated with Canavans disease, giving rise to an increase in NAA levels. ${ }^{27}$

\section{Choline}

Choline is not synthesized in the brain, hence, it is absorbed from the plasma as free choline or as phoshphatidyl choline produced by the liver. Cellular density, free choline, phosphocholine, and glycerophosphocholine are the strongest determinants of $1 \mathrm{H}$ MRS choline peak. Choline is a constituent of phospholipid metabolism of cell membranes and reflects membrane turnover. ${ }^{25}$ Choline is involved in the synthesis of neurotransmitter acetylcholine and phospholipids. Increased choline probably reflects increased membrane synthesis and/or increased number of cells.

\section{Creatine}

Cr peak at 3.03 ppm using MRS contains contributions from $\mathrm{Cr}, \mathrm{Cr}$ phosphate, and, to a lesser degree, from amino butyric acid, lysine, and glutathione. An additional peak for $\mathrm{Cr}$ may be visible at $3.94 \mathrm{ppm}$. Therefore, the $\mathrm{Cr}$ peak is sometimes referred to as total $\mathrm{Cr}$. Cr probably plays a role in maintaining energy-dependent systems in brain cells by serving as a reserve for high-energy phosphates and as a buffer in adenosine triphosphate (ATP) and adenosine diphosphate (ADP) reservoir. ${ }^{25} \mathrm{Cr}$ also functions as an osmolyte responding to osmotic (Donnan) forces. Thus, $\mathrm{Cr}$ is increased in hypermetabolic and hyperosmolar states and decreased in hypometabolic and hypoosmolar states. Total $\mathrm{Cr}$ present in $\mathrm{Cr}$ 
and phosphocreatine MRS resonance changes to maintain osmotic equilibrium, ${ }^{28}$ in normal spectra, $\mathrm{Cr}$ is located to the immediate fight of Cho and is the third-highest peak. This peak appears to be tightly controlled under physiologic conditions, suggesting a possible role as a fixed internal reference for metabolite amplitude or area.

\section{Lactate}

Lactate MRS peak consists of two distinct resonant peaks called a doublet, and is caused by magnetic field interactions between adjacent protons ( $\mathrm{J}$ coupling). Lactate doublet occurs at $1.32 \mathrm{ppm}$ and second peak occurs at $4.1 \mathrm{ppm}$. Normally, lactate levels in the brain are low. The presence of lactate generally indicates that the normal cellular oxidative respiration mechanism is no longer in effect, and that carbohydrate catabolism is taking place. Lactate can play as a neuromodulator by altering the excitability of local neurons. ${ }^{29}$

\section{Glutamate and glutamine}

Glutamate, an excitatory neurotransmitter, is the most abundant of the amino acids in the brain. It plays a role in the mitochondrial metabolism. ${ }^{30}$ Glutamine is a metabolite of glutamate. These two metabolites resonate closely together and are represented by their sum as peaks located between 2.1 and $2.5 \mathrm{ppm}$. Glutamate metabolism is particularly important in detoxification and excitatory neurotransmission. A disturbance of the normal glutamate/glutamine regulatory metabolism (excitotoxicity hypothesis) has been suggested to be present in various neurologic disorders such as cerebral stroke, prolonged seizures, neurodegenerative disorders, hypoglycemia, and mitochondrial encephalopathy.

\section{Myoinositol}

Myoinositol is a metabolite involved in hormone sensitive neuroreception and is a possible precursor of glucuronic acid, which detoxifies xenobiotics by conjugation. ${ }^{30}$ The myoinositol peaks occur at $3.56 \mathrm{ppm}$. Myoinositol has been suggested as a possible degradation product of myelin and a marker of glial cells. ${ }^{31}$ In addition, a triphosphorylated derivative of myoinositol, myoinositol-1, 4, 5-triphosphate, is believed to act as a second messenger of intracellular calcium-mobilizing hormones. Myoinositol has been found to be increased in patients with Alzheimer's disease (AD) ${ }^{32}$ or hepatic encephalopathy. ${ }^{33}$

\section{Lipids}

Membrane lipids in the brain have very short relaxation times and are normally not observed unless very short TEs are used. The protons associated with lipids produce peaks at $0.8,1.2,1.5$, and $6 \mathrm{ppm}$. These peaks comprise methyl, methylene, allelic, and the vinyl protons of unsaturated fatty acids. ${ }^{34}$ These metabolites may be increased in high-grade astrocytomas and meningiomas and may reflect necrotic processes. $^{35}$

\section{Plasma-circulating metabolites and their clinical significance}

Biomarkers in body fluids such as CSF, plasma, and serum could be utilized to increase the accuracy of diagnosis for cognitive decline and prediction of mild cognitive impairment (MCI) progression. CSF presents a good resource for research into neurodegenerative diseases, but its clinical application is limited by the invasive nature of the procedure, particularly in elderly populations, and the requirement of highly trained personnel, making it unsuitable for routine application.

Plasma is a complex body fluid containing proteins, peptides, lipids and metabolites that reflect physiological activity and pathology in various body organs, including the CNS. In humans about $500 \mathrm{ml}$ of CSF is absorbed into blood daily, ${ }^{36}$ making blood a suitable source of neurodegenerative disease biomarkers. The ease of a venepuncture compared to a lumbar puncture allows for repeatability, making it suitable for application in clinical trials to evaluate diseasemodifying treatments. Blood tests for diabetes, cholesterol levels, and apolipoprotein E genotyping are already available to clinicians for assessment of AD risk factors.

According to the current consensus criteria proposed by the National Institute on Aging (NIA), ${ }^{37,38}$ ideal biomarkers for AD should: 1) detect the fundamental CNS pathophysiology of $\mathrm{AD}$ and be validated in neuropathologically confirmed cases, 2) should have a diagnostic sensitivity $>85 \%$ for detecting $\mathrm{AD}$ and a specificity $>75 \%$ for distinguishing between other dementias, 3) should detect any beneficial effects of disease-modifying therapy, 4) should be reliable, reproducible, noninvasive, simple, and inexpensive, and 5) be confirmed by at least two independent studies conducted by qualified investigators with the results published in peerreviewed journals. Key features of a biomarker include its ability to detect disease processes at early and preferably preclinical stages of the disease and variation with disease progression and severity.

\section{Biomarkers of oxidative stress}

There are two hypotheses relating peripheral oxidative stress to neurodegeneration. The first suggests that oxidative stress 
initially develops in the periphery with a variety of possible causes, and results in reduction of CNS antioxidants, finally leading to oxidative damage and neurodegeneration. ${ }^{39}$ The second is that the CNS is the original place where oxidative stress begins, and then several different metabolic endproducts are formed and transported into the periphery. ${ }^{39}$

Lipid peroxidation (malondialdehyde, 4-hydroxynonenal, F2-idoprostanes), protein carbonyls (protein carbonyls and nitrotyrosine) and DNA oxidation (8-hydroxy2-deoxyguanosine, single-strand breaks) in the AD brain have been reported as markers of oxidative damage. ${ }^{40}$ However, oxidative DNA damage is not an effective diagnostic biomarker for AD patients. ${ }^{39}$ Results of proteomics studies provide evidence that oxidized proteins in plasma may be useful biomarkers in MCI and AD. Using ELISA based studies, levels of protein carbonyls in AD patients were found to be lower in serum but not in CSF and plasma, and levels of nitrotyrosine did not differ between AD patients and controls. ${ }^{41}$

Isoprostane is one of the products of lipid peroxidation, formed by free radical-mediated peroxidation of polyunsaturated fatty acid. ${ }^{42}$ Although isoprostane is not neurotoxic, elevated levels of F2-isoprostane (F2-IsoP) have been observed in AD CSF and brain. ${ }^{43,44}$ In a longitudinal study, levels of CSF F2-IsoPs in AD patients were significantly increased during the follow-up period, and also significantly declined in patients accepting antioxidant treatment. ${ }^{45}$ The significance of F2-isoprostane in AD and MCI plasma is still controversial. Pratico and colleagues found high levels of F2-IsoP in plasma, CSF, and urine of MCI patients, ${ }^{46}$ and the same research group showed similar results in AD patients. ${ }^{44}$ In a recent study, mean plasma F2-IsoP levels were not increased in $\mathrm{AD}$ or $\mathrm{MCI}$, but a high percentage of antioxidant use in $\mathrm{MCI}(74 \%)$ and $\mathrm{AD}(88 \%)$ in this research may have influenced the F2-IsoP concentrations in plasma. ${ }^{47}$

\section{Biomarkers of inflammation}

It has been established that molecules representing inflammatory processes occur in the $\mathrm{AD}$ brain ${ }^{40,48}$ and the presence of activated microglia and astrocytes increases the level of pro-inflammatory cytokines, including interleukin-1 (IL-1), interleukin-6 (IL-6), tumor necrosis factor $\alpha$ (TNF- $\alpha$ ), as well as acute phase proteins, such as $\mathrm{C}$-reactive protein (CRP) and $\alpha 1$-antichymotrypsin (ACT). ${ }^{48,49}$

There is experimental as well as clinical evidence to support the hypothesis that inflammatory processes might be involved in the early stages of $\mathrm{AD}$, even before amyloid deposition or the appearance of clinical symptoms. ${ }^{50-52}$
However, the results on inflammatory markers in the peripheral circulations of $\mathrm{AD}$ and $\mathrm{MCI}$ patients are controversial. Several longitudinal studies have shown that inflammatory markers in serum or plasma are related to cognitive decline. High serum ACT was associated with an increased risk of cognitive decline. ${ }^{53}$ High-sensitivity CRP significantly increased risk of combined dementias, AD, and vascular dementia. ${ }^{54}$ Serum IL-6 and CRP were prospectively related to cognitive decline in well functioning elders. ${ }^{55}$ High levels of ACT, IL-6, and CRP in plasma were associated with an increased risk of $\mathrm{AD}$ respectively. ${ }^{50} \mathrm{~A}$ recent study used ELISA to measure 120 known signaling proteins involved in central and peripheral immune and inflammatory mechanisms in plasma from AD subjects and nondemented controls. $^{56}$

\section{Connecting neurological clinical presentation with plasma changes}

The identification of peripheral metabolomic signatures of neurological illnesses is likely to have more potential for translation into the clinical realm. Importantly it is critical in future studies to verify that there are disease related signatures, that may be subrogates of changes in the brain, and hence could provide clinical information and clues about disease pathogenesis. ${ }^{57}$ On the other hand, there is a limited amount of research correlating findings seen peripherally and centrally (brain tissue or CSF). However, an obvious challenge to conducting metabolomic studies linking peripheral and central is the limited access to brain tissue. CSF can be collected following a lumbar puncture, and despite that this fluid is commonly used as a proxy for brain changes in CNS disorders, ${ }^{58}$ the need for special training for collection and the risk associated to the procedure, have limited the amount of studies conducted using this resource. Nevertheless, some evidence seems to suggest that central CSF changes in potential biomarkers might be correlated with changes in the periphery (blood; plasma or serum). For instance measurement of inflammatory markers in paired plasma/CSF samples of healthy human volunteers revealed a correlation between central and peripheral levels. ${ }^{59}$ This also seems to be the case for some metabolites. Plasmafree tryptophan is clearly correlated with brain tryptophan concentration. Indeed, it has been suggested that plasmafree tryptophan concentration provides an index of CSF tryptophan and 5-HT turnover in the brain. ${ }^{60}$ Likewise, CSF and serum/plasma concentrations of vitamin biomarkers are significantly correlated. Strikingly, the correlation between serum and CSF-folate can be as high 0.69. ${ }^{61}$ 
Another example is the levels of the side chain oxidized oxysterol 24S-hydroxycholesterol, a potential maker of brain injury, which forms almost exclusively in the brain and whose levels in plasma and CSF are highly correlated. ${ }^{62}$

Nonetheless, limited amount of evidence also suggests that abnormalities in the blood level of certain metabolites (plasma or serum) might not be correlated with central abnormalities. ${ }^{64}$ Thus, additional research using metabolomics-based approaches is needed to define metabolites whose central and peripheral levels are linked and how these correlations are influence by neurological illnesses. Comparative studies in CSF (or postmortem brain tissue itself) and blood could help map central and peripheral changes in neurodegenerative disorders, enabling a more accessible way for biomarker development in blood but ensuring that these peripheral biomarkers are reflective of central changes. Indeed, the process of linking the metabolic profiles defined on blood and specimens derived from invasive sampling (eg, CSF) is critical to identify 'bridging biomarkers' of disease, as well as both efficacy and toxicity medication.

\section{Metabolomic signatures in neurological disorders}

Quinones and Daouk were able to identify a distinctive signature of highly correlated metabolites in a set of four patients, three of whom had lower motor neuron (LMN) disease. Furthermore, they defined a metabolic signature that was independent of the drug riluzole (illness-related) by profiling patients who were off medication. ${ }^{64}$ Collectively, these results suggest that metabolomic studies can be used to ascertain metabolic signatures of disease using easily accessible samples like plasma.

A recent study by Bogdanov and colleagues ${ }^{65}$ conducted interesting work defining metabolomic signatures in Parkinson's disease (PD). They included 25 controls and 66 PD patients and used liquid chromatography followed by electrochemical detection (LCECA) to create a database representing 2,000 signals from plasma samples. Multivariate data analysis revealed separation of the metabolomic profile of medicated and unmedicated patients and controls. Markers of oxidative damage and the antioxidant glutathione were significantly increased in PD patients. Uric acid levels were significantly decreased. Interestingly, alike glutathione, uric acid is also an antioxidant and higher uric acid levels lower risk for PD and slow the progression of the illness.

Another neuropsychiatric disorder in which metabolomic studies have been performed is Huntington's disease (HD).
In an interesting cross-species study, serum samples from a transgenic mouse model of HD and patients with HD were studied using gas chromatography-time-of-flight-mass spectrometry. ${ }^{66}$ The investigators observed clear differences in metabolic profiles between transgenic mice and wild-type littermates (healthy mice), with a trend for similar differences in human patients and controls. ${ }^{66}$ Potential markers were related to fatty acid breakdown (including glycerol and malonate) and also to certain aliphatic amino acids. Taken together, the findings of this study suggest the interesting possibility that the metabolites responsible for distinguishing transgenic mice also comprised a metabolic signature tentatively associated with the human disease. Results from another murine model of HD have also highlighted the usefulness of metabolomics to study disease pathogenesis and identify potential biomarkers. ${ }^{67}$

Metabolomic analysis of blood plasma was performed on nine depressed, 11 remitted, and 10 never-depressed older adults. ${ }^{68}$ Hundreds of metabolites were measured using GC-MS. Metabolites that were altered in currently depressed patients when compared with controls included several fatty acids, glycerol and gamma-aminobutyric acid (GABA). Analyses comparing concentrations in remitted and currently depressed patients revealed a pattern of metabolite alterations similar to the control vs. currently depressed analyses. One difference observed in the remitted patients relative to the depressed patients was elevation of the concentration of the ketone 3hydroxybutanoic acid.

Moreover, major changes were noted in two phospholipids classes, phosphotidylethanolamine (PE) and phosphotidylcholine (PC), suggesting that phospholipids that play a key role in proper membrane structure and function seem to be impaired in patients with schizophrenia. ${ }^{57,69}$

The metabolic profile of children diagnosed with autistic disorder with regressive onset was found to be severely abnormal. ${ }^{70}$ The autistic children were found to have significant decreases in methionine levels and in the ratio of plasma S-adenosylmethionine (SAM) to S-adenosylhomocysteine (SAM/SAH ratio), an index of methylation capacity. Total glutathione (GSH, the major intracellular antioxidant) levels were decreased and oxidized glutathione disulfide (GSSG) was increased, resulting in a threefold reduction in the redox ratio of reduced (active) GSH to oxidized (inactive) glutathione (GSH/GSSG). Cysteine, the rate-limiting amino acid for glutathione synthesis, was significantly decreased relative to the control children suggesting that GSH synthesis was insufficient to maintain redox homeostasis. This profile was ascertained recently by Al-Gadani and colleagues, ${ }^{71}$ 
in a study of oxidative stress and antioxidant status of Saudi autistic children. They recorded a significant decrease in glutathione concentration in autistic compared to control. Recorded impaired metabolites related to neurological diseases are listed in Table 1.

\section{Sensitivity and specificity of biochemical markers of neurological diseases}

With the move toward development of disease-modifying treatments, there is a need for more specific diagnosis of neurological diseases. The diagnostic accuracy of a biomarker is most commonly measured by calculating its sensitivity and specificity. Sensitivity is the proportion of patients who are correctly categorized as having disease among those who truly have the disease. Similarly, specificity is the proportion of patients who are correctly categorized as not having the disease among all patients who truly don't have the disease. Since most diagnostic biomarkers provide results in the continuous scale, the sensitivity and specificity of the metabolite depends on the specific threshold selected. ${ }^{102}$

Receiver-operating characteristic (ROC) curve analysis is a useful tool in assessment of biomarker accuracy. Its advantages include testing accuracy across the entire range of scores and thereby not requiring a predetermined cut-off point, in addition to easily examined visual and statistical comparisons across tests or scores, and, finally, independence from outcome prevalence. Further, ROC curve analysis is a useful tool for evaluating the accuracy of a statistical model that classifies subjects into one of two categories. Diagnostic models are different from predictive and prognostic models in that the latter incorporate time-to-event analysis, for which censored data may pose a weakness of the model, or the reference standard. However, with the appropriate use of ROC curves, investigators of biomarkers can improve their research and presentation of results. ${ }^{103}$

Plasma and serum biochemical markers proposed for $\mathrm{AD}$ are based on pathophysiologic processes such as amyloid plaque formation (amyloid $\beta$-protein $[A \beta], A \beta$ autoantibodies, platelet amyloid precursor protein [APP] isoforms, inflammation [cytokines], oxidative stress [vitamin E, isoprostanes], lipid metabolism [apolipoprotein E, 24S-hydroxycholesterol], and vascular disease [homocysteine, lipoprotein (a)]). ${ }^{104}$ Most proteins or metabolites evaluated in plasma or serum thus far are, at best, biological correlates of AD: levels are statistically different in $\mathrm{AD}$ versus controls in some cohorts, but they lack sensitivity or specificity for diagnosis or for tracking response to therapy. Recently, quantitative analysis revealed an increased concentration in five plasma proteins in MCI and $\mathrm{AD}$ patients compared to healthy subjects: epidermal growth factor (EGF), glial cell-derived neurotrophic factor (GDNF) and MIP1 $\delta$ (in AD), MIP4 (in MCI), and RANTES (in MCI and AD). ROC analysis predicted a sensitivity of $65 \%-75 \%$ and a specificity of $52 \%-63 \%$ when comparing healthy controls versus MCI or AD. Depression without any significant cognitive deficits did not cause any significant changes. Depressed patients with significant cognitive impairment were not different from MCI patients. ${ }^{106}$ Approaches combining panels of existing biomarkers or surveying the range of proteins in plasma (proteomics) show promise for discovering biomarker profiles that are characteristic of AD, yet distinct from nondemented patients or patients with other forms of dementia.

Plasma markers for stroke could be useful in diagnosis and prognosis and in prediction of response of stroke patients to therapy. PARK7 and nucleoside diphosphate kinase A (NDKA) are increased in human postmortem CSF, a model of global brain insult, suggesting that measurement in CSF and, more importantly, in plasma may be useful as a biomarker of stroke. Increases in both biomarkers were highly significant, with sensitivities of 54\%-91\% for PARK 7 and 70\%-90\% for NDKA and specificities of $80 \%-97 \%$ for PARK7 and 90\%-97\% for NDKA. The concentrations of both biomarkers increased within three hours of stroke onset. $^{106}$

Receiver operating characteristic curves were constructed, showing test sensitivities at given specificities for PD. Myocardial 6-[18F]fluorodopamine-derived radioactivity distinguished PD from multiple system atrophy (MSA; $83 \%$ sensitivity at $80 \%$ specificity, $100 \%$ sensitivity, respectively). ${ }^{107}$

\section{Overview of metabolomic methodology}

For metabolomic analyses, the analytical technique must therefore be really suitable for a diverse range of small endogenous metabolites in various concentrations. Furthermore, it must be able to separate compounds with different physical and chemical properties, and be very reliable. Currently, most metabolomic analyses are performed with nuclear magnetic resonance spectroscopy (NMR), gas chromatography combined with mass spectrometry (GC-MS), liquid chromatography combined with MS (LC-MS), and capillary electrophoresis. 
Table I Metabolic signatures in neurological disorders

\begin{tabular}{|c|c|c|c|c|}
\hline Metabolite & Biological sample & $\begin{array}{l}\text { Level } \\
\text { Up/Down }\end{array}$ & Neurological disorder & $\begin{array}{l}\text { Citation } \\
\text { number }\end{array}$ \\
\hline Epidermal growth factor (EGF) & Plasma & Up & Alzheimer's disease (AD) & 72 \\
\hline $\begin{array}{l}\text { Total hydroxyoctadecadienoic acid } \\
\text { (tHODE) }\end{array}$ & Plasma & Up & Alzheimer's disease (AD) & 73 \\
\hline Oxidized peroxiredoxin & RBC & & & \\
\hline $\begin{array}{l}\text { - } \mathrm{Na}(+) / \mathrm{K}(+) \text { ATPase } \\
\text { - Creatine kinase } \\
\text { - ADPase } \\
\text { - Lactate }\end{array}$ & Plasma & Up & Autism & 74 \\
\hline Substance P (SP) & $\begin{array}{l}\text { Plasma } \\
\text { CSF }\end{array}$ & $\begin{array}{l}\text { Up } \\
\text { Up }\end{array}$ & $\begin{array}{l}\text { Post-stroke depression } \\
\text { (PSD) }\end{array}$ & 75 \\
\hline Malondialdehyde (MDA) & Plasma & Up & $\begin{array}{l}\text { Parkinson's disease (PD) } \\
\text { Autism }\end{array}$ & $\begin{array}{l}76 \\
71\end{array}$ \\
\hline $\begin{array}{l}\text { Circulating cell-free deoxyribonucleic } \\
\text { acid (DNA) }\end{array}$ & Plasma & & Parkinson's disease (PD) & 77 \\
\hline 8-hydroxydeoxyguanosine (8-OHdG) & Leukocyte & $U_{p}$ & Parkinson's disease (PD) & 78 \\
\hline $\begin{array}{l}\text { Glutathione peroxidase (GPx) } \\
\text { Vitamin E (Vit E) }\end{array}$ & $\begin{array}{l}\text { Plasma } \\
\text { Erythrocyte }\end{array}$ & $\begin{array}{l}\text { Up } \\
\text { Down }\end{array}$ & Autism & 71 \\
\hline $\begin{array}{l}\text { Dopamine transporter immunoreactivity } \\
\text { (DAT-IR) }\end{array}$ & $\begin{array}{l}\text { Peripheral blood } \\
\text { lymphocytes (PBL) }\end{array}$ & Down & $\begin{array}{l}\text { Extra pyramidal variant of multiple } \\
\text { system atrophy }\end{array}$ & 79 \\
\hline Endogenous hydrogen sulfide ( $\mathrm{H} 2 \mathrm{~S})$ & Plasma & Down & (AD), Vascular & 80 \\
\hline Homocysteine (Hcy) & & $U_{p}$ & $\begin{array}{l}\text { Dementia (VD), Cerebrovascular } \\
\text { disease (CVD) }\end{array}$ & \\
\hline Endotoxin/lipopolysaccharide (LPS) & Plasma & Up & $\begin{array}{l}\text { Sporadic amyotrophic lateral } \\
\text { sclerosis (sALS) Alzheimer's (AD) }\end{array}$ & 81 \\
\hline Stem cell factor (SCF) & $\begin{array}{l}\text { Plasma } \\
\text { CSF }\end{array}$ & Down & Alzheimer's disease (AD) & 82 \\
\hline Zinc (Zn) & Serum & Down & Mild cognitive impairment (MCl) & 83 \\
\hline Alpha-I-antichymotrypsin (ACT) & Plasma & $U_{p}$ & Alzheimer's disease (AD) & 84 \\
\hline $\begin{array}{l}\text { - Intra erythrocyte nonprotein-bound } \\
\text { iron (NPBI; ie, free iron) } \\
\text { - NPBI, } F(2) \text {-isoprostanes }\end{array}$ & Plasma & Up & Rett syndrome (RS) & 85 \\
\hline Immunoglobulin (IgG, IgM) & Plasma & Down & Autism & 86 \\
\hline $\begin{array}{l}\text { Glutathione redox state } \\
\text { GSH/GSSG }\end{array}$ & $\begin{array}{l}\text { Lymphoblastoid } \\
\text { cells (LCLS) } \\
\text { extracts }\end{array}$ & Down & Autism & 87 \\
\hline Total creatine $(\mathrm{tCr})$ & Brain & Down & $\begin{array}{l}\text { Creatine transporter (SLC6A8) } \\
\text { deficiency syndrome }\end{array}$ & 88 \\
\hline Hormone/cytokine leptin & Plasma & $U_{p}$ & Autism spectrum disorders (ASD) & 89 \\
\hline Apelin & Plasma & Down & Autistic spectrum disorder (ASD) & 90 \\
\hline Vasopressin (AVP) & Plasma & $U_{p}$ & & \\
\hline Phospholipid omega-3/ & Plasma & $U_{p}$ & Autism & 91 \\
\hline Omega-6 PUFA fractions & & Up & & 92 \\
\hline Magnesium & Plasma & $U_{p}$ & Autism & 93 \\
\hline Gamma-aminobutyric acid (GABA) & Plasma & $U_{p}$ & $\begin{array}{l}\text { Autistic disorder and Attention- } \\
\text { deficit/hyperactivity disorder }\end{array}$ & 94 \\
\hline & Blood & & Autistic disorder & 95 \\
\hline - Phenylalanine & Plasma & Down & Autism & 96 \\
\hline - Glutamine & & Down & Attention deficit/hyperactivity & \\
\hline - Glycine & & Up & disorder (ADHD) & \\
\hline - Lysine & & Up & & \\
\hline
\end{tabular}


Table I (Continued)

\begin{tabular}{|c|c|c|c|c|}
\hline Metabolite & Biological sample & $\begin{array}{l}\text { Level } \\
\text { Up/Down }\end{array}$ & Neurological disorder & $\begin{array}{l}\text { Citation } \\
\text { number }\end{array}$ \\
\hline Serotonin $(5-\mathrm{HT})$ & Whole blood & Up & Autism & 97 \\
\hline $\begin{array}{l}\text { C-terminally directed beta-endorphin } \\
\text { protein immunoreactivity } \\
\text { (C-ter-beta- EP-ir) }\end{array}$ & & $U_{p}$ & & 98 \\
\hline Oxytocin & Plasma & Down & Autism & 99 \\
\hline Beta-endorphin & Plasma & Down & Autism & 100 \\
\hline Neopterin & Plasma & Down & Autism & 101 \\
\hline
\end{tabular}

\section{NMR spectroscopy-based metabolomics}

NMR is an analytical platform that allows the reliable detection and quantification of wide range of metabolites (high universality, ie, will detect any hydrogen containing metabolite) present in complex biological fluids at micromolar concentrations. "Whole" samples can be analyzed, thus NMR is considered to be nondestructive technique with low handling and preprocessing times. There are multiple examples in the literature of the application of NMR metabolomics in CNS disorders including Huntington's results in a murine model, ${ }^{67}$ studies on tissue and plasma in a rodent model of traumatic brain injury, ${ }^{108}$ and studies in patients with schizophrenia ${ }^{109}$ (Figure 3).

\section{MS-based methods for metabolomics}

MS-based approaches represent universal, yet sensitive tools to characterize, identify, and quantify the plethora of compounds present in a biological tissue or body fluid. ${ }^{110}$ Prior to analysis, biological samples need to be separated using chromatography, commonly either gas (GC) or liquid chromatography (LC). Subsequently, metabolites are identified using a mass spectrometer. The use of MS for

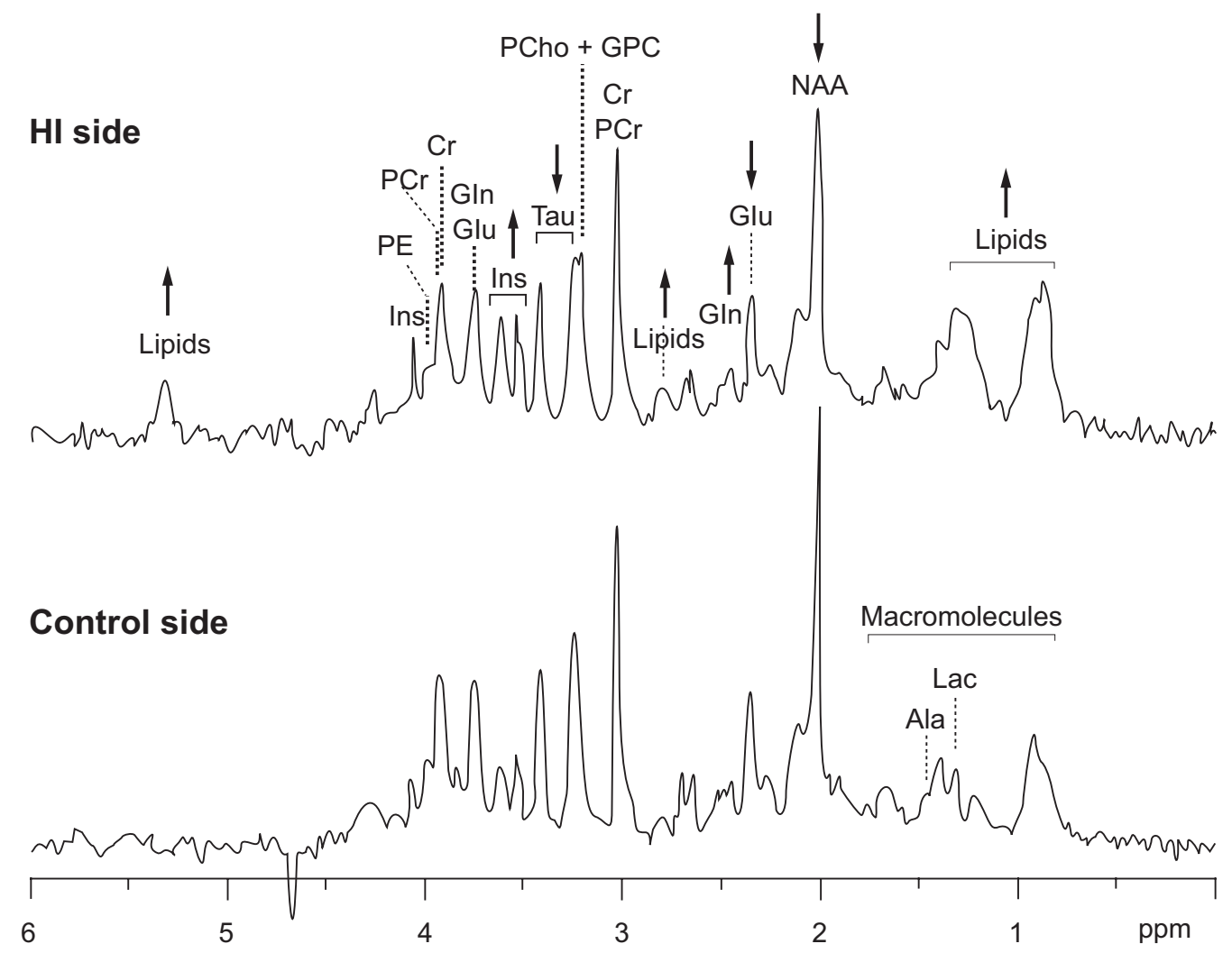

Figure 3 IH-NMR spectra from post-hypoxia injured $(\mathrm{HI})$ rat hippocampus (top) and control (bottom). Arrows indicate the direction of changes in certain neurochemicals on the $\mathrm{HI}$ side when compared with the control side. ${ }^{108}$

Abbreviations: Ala, ; Cr, creative; Gln, glutamine; Gln, glutamic acid; GPC, ; NAA, ; Ins, ; PE, ; PCr, phosphocreative, PCho, ; Tau, . 
A)

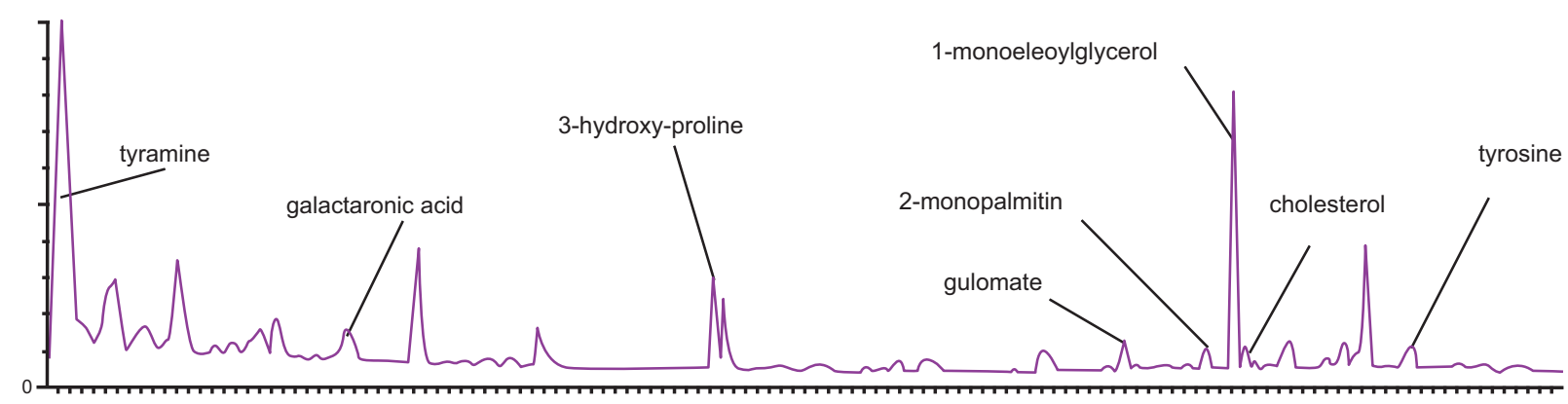

B)

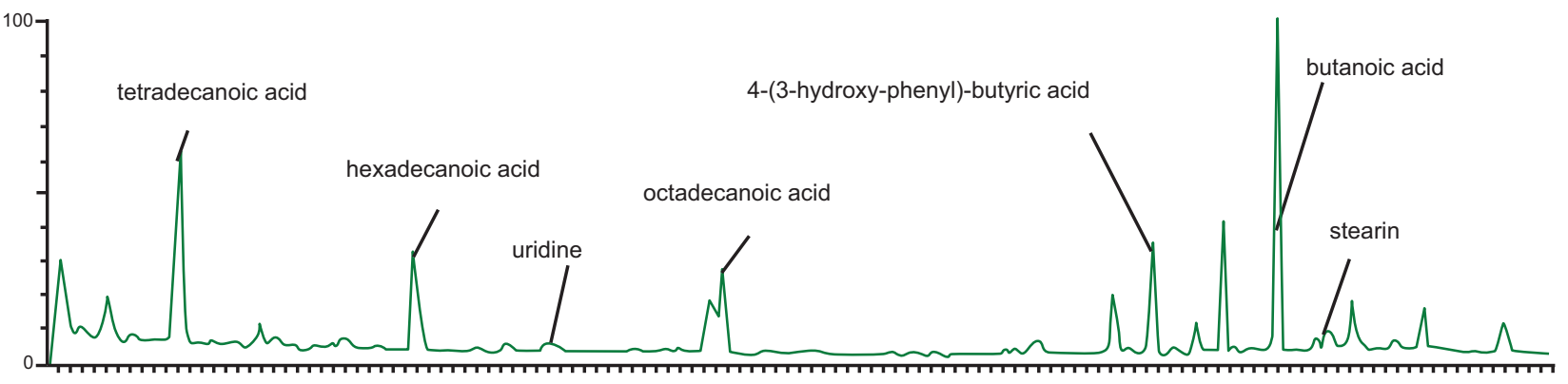

C)

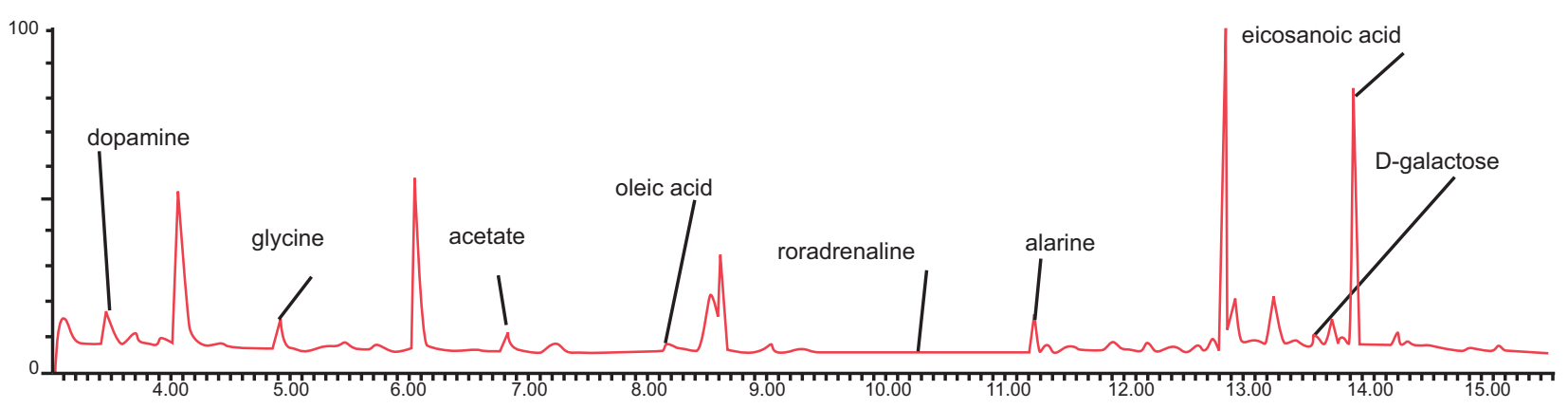

Figure 4 Typical GC-MS total ion current (TIC) chromatograms of urine from treated group A), Kidney deficiency syndrome group B) and control group C). Abbreviations: GC-MS, gas chromatography-mass spectrometry.

metabolomics research in CNS disorders provides a number of advantages, allowing the detection of many metabolite classes at physiological concentrations including amino and organic acids, fatty acids, sugars, sugar phosphates, bile acids, lipids, and nucleotide bases. MS has the ability to identify known as well as new metabolites (not currently described in databases) in a relatively straightforward fashion.

\section{GC-MS technique}

The combination of gas chromatography (GC) with MS is a well developed and robust tool that has been applied for many years. Thus, GC-MS has been one of the major analytical drivers in the early development of metabolomics. GC-MS allows the detection and quantification of many metabolite classes including amino and organic acids, fatty acids and some lipids, sugars, sugar alcohols and phosphates, amines, amides, and thiol-containing metabolites. This technique has become highly developed because of high sensitivity, high chromatographic resolution, a wide range of detectable metabolite classes, and the ability to identify metabolites through the production of mass spectral/retention index libraries or by comparison to commercially available libraries. ${ }^{66,68}$

\section{LC-MS}

This flexible and sensitive analytical platform used to characterize, identify, and quantify a large number of compounds in a biological sample where metabolites are present at very different concentrations. ${ }^{111} \mathrm{LC}$ encompasses a range of systems including high-performance liquid chromatography (HPLC) and capillary liquid chromatography, among others. Metabolic profiling using LC-MS can be hindered by issues related to the chromatographic resolution, effect of matrix effects (ionization suppression) on co-eluting metabolites and influence of column chemistries employed. Nonetheless, LC-MS has been used successfully for metabolomic studies in CNS disorders (eg, virus infection-induced neurodegeneration). ${ }^{12}$ 


\section{Capillary electrophoresis}

Capillary electrophoresis (CE) is an analytical separation technique capable of high-resolution separation of a diverse range of chemical compounds. ${ }^{113}$ It is particularly suitable for the separation of polar and charged compounds. It is a more powerful technique than $\mathrm{LC}$ with respect to separation efficiency, and the amount of sample required for analysis is small. When CE is used for the analysis of serum or cerebrospinal fluid, deproteinization is often applied using ultrafiltration. The main reason for the deproteinization is to prevent precipitation of the proteins in the capillary or adsorption to the capillary wall. However, human serum has also been analyzed directly by $\mathrm{CE}$ for the determination of organic acids. ${ }^{113}$

\section{Concluding remarks}

The introduction and concepts of metabolomics enabling the study of neurological diseases based on profiling a multitude of biochemical components related to brain metabolism. This approach is considered to have the potential to revolutionize medical practice in preventing, predicting, and personalizing brain health care. Through metabolomic approach, plasma and serum, could be utilized to increase the accuracy of diagnosis of neurological disorders. Metabolomic approach is a promising tool for the investigation of large number of small samples rapidly which could reduce the manual labor of technicians and to explore unexpected properties of biological systems which could help in recording more markers related to brain diseases. If metabolomic information can be translated into diagnostic tests, metabolomic approach could provide earlier, faster, and more accurate diagnoses for many diseases. Potential biomarkers require evaluation of their sensitivity, specificity, and there is currently no biomarker candidate that fulfills all the criteria for validation as a biomarker.

\section{Acknowledgments}

The authors wish to express their profound thanks to SABIC Company, Kingdom of Saudi Arabia for the support of this review and related work. Thanks are also expressed to Miss Nada El-Ghawaby for her effort in designing and improving the quality of the art work presented in the manuscript. The authors report no conflicts of interest in this work.

\section{References}

1. Gershon ES, Goldin LR. Clinical methods in psychiatric genetics. I. Robustness of genetic marker investigative strategies. Acta Psychiatr Scand. 1986;74:113-118.

2. Leboyer M, Leboyer M, Bellivier F, et al. Psychiatric genetics: search for phenotypes. Trends Neurosci. 1998;21:102-105.
3. Biomarkers Definitions Working Group, 2001. Biomarkers and surrogate endpoints: preferred definitions and conceptual framework. Clin Pharmacol Ther. 2001;69:89-95.

4. Vasan RS. Biomarkers of cardiovascular disease: molecular basis and practical considerations. Circulation. 2006;113:2335-2362.

5. Hood L, Heath JR, Phelps ME, Lin B. Systems biology and new technologies enable predictive and preventative medicine. Science. 2004;306:640-643.

6. Kristal BS, Kaddurah-Daouk R, Beal MF, Matson WR. Metabolomics: concept and potential neuroscience application. In: Handbook of Neurochemistry and Molecular Neurobiology: Brain Energetics. Integration of Molecular and Cellular Processes. New York, NY: Springer; 2007. p. 889-912.

7. Kaddurah-Daouk R, Kristal BS, Weinshilboum RM. Metabolomics: a global biochemical approach to drug response and disease. Аnnu Rev Pharmacol Toxicol. 2008;48:653-683.

8. Cacabelos R. Pharmacogenomics and therapeutic strategies for dementia. Expert Rev Mol Diagn. 2009;9:567-611.

9. Lindon JC, Holmes E, Nicholson JK. Metabonomics and its role in drug development and disease diagnosis. Expert Rev Mol Diagn. 2004; 4:189-199.

10. Holmes E, Wilson ID, Nicholson JK. Metabolic phenotyping in health and disease. Cell. 2008;134:714-717.

11. Wishart D. Applications of metabolomics in drug discovery and development. Drugs R D. 2008;9:307-322.

12. Dunckley T, Coon K, Stephan A. Discovery and development of biomarkers of neurological disease. Drug Discov Today. 2005;10: 326-334.

13. Dekosky ST, Marek K. Looking backward to move forward: early detection of neurodegenerative disorders. Science. 2003;302: 830-834.

14. Kell DB. Metabolomics and systems biology: making sense of the soup. Curr Opin Microbiol. 2004;7:296-307.

15. Wang M, Lamers RJ, Korthout HA, et al. Metabolomics in the context of systems biology: bridging traditional Chinese medicine and molecular pharmacology. Phytother Res. 2005;19:173-182.

16. Wang QZ, Wu CY, Chen T, Chen X, Zhao XM. Integrating metabolomics into a systems biology framework to exploit metabolic complexity: strategies and applications in microorganisms. Appl Microbiol Biotechnol. 2006;70(2):151-161.

17. Kochhar S, Jacobs DM, Ramadan Z, Berruex F, Fuerholz A, Fay LB. Probing gender-specific metabolism differences in humans by nuclear magnetic resonance-based metabonomics. Anal Biochem. 2006;352:274-281.

18. Slupsky CM, Rankin KN, Wagner J, et al. Investigations of the effects of gender, diurnal variation, and age in human urinary metabolomic profiles. Anal Chem. 2007;79:6995-7004.

19. Lenz EM, Bright J, Wilson ID, Morgan SR, Nash AF. A 1H NMRbased metabonomic study of urine and plasma samples obtained from healthy human subjects. J Pharm Biomed Anal. 2003;33: 1103-1115.

20. Lenz EM, Bright J, Wilson ID, et al. Metabonomics, dietary influences and cultural differences: a $1 \mathrm{H}$ NMR-based study of urine samples obtained from healthy British and Swedish subjects. J Pharm Biomed Anal. 2004;36:841-849.

21. Walsh MC, Brennan L, Malthouse JP, Roche HM, Gibney MJ. Effect of acute dietary standardization on the urinary, plasma, and salivary metabolomic profiles of healthy humans. Am J Clin Nutr. 2006;84: 531-539.

22. Beckonert O, Keun H, Ebbels T, et al. Metabolic profiling, metabolomic and metabonomic procedures for NMR spectroscopy of urine, plasma, serum and tissue extracts. Nat Protoc. 2007;11:2692-2703.

23. Fiehn O, Robertson D, Griffin J, et al. The metabolomics standard initiative (MSI). Metabolomics. 2007;3:175-178.

24. Simmons ML, Frondoza CG, Coyle JT. Immunocytochemical localization of $\mathrm{N}$-acetyl aspartate with monoclonal antibodies. Neuroscience. 1991;45:37-45. 
25. Miller BL. A review of chemical issues in 1H NMR spectroscopy: N-acetyl-L-aspartate, creatine and choline. NMR Biomed. 1991; 4:47-52.

26. Spielman DL, Lim KO. Estimating NAA in cortical gray matter with applications for measuring changes due to aging. Magn Reson Med. 1997;37:372-377.

27. Wittsack HJ, Kugel H, Roth B, et al. Quantitative measurements with localized H-1 MR spectroscopy in children with Canavan's disease. J Magn Resort Imaging. 1996;6:889-893.

28. Ross B, Michaelis T. Clinical applications of magnetic resonance spectroscopy. Mag Res Q. 1994;10:191-247.

29. Sanders JA. Magnetic resonance spectroscopy. In: Orrison WW, Lewine JD, Sanders JA, et al. (editors). Functional Brain Imaging. St. Louis, MO: Mosby; 1995. p. 419-467.

30. van der Knaap MS, Ross B, Valk J. Use of MR in inborn errors of metabolism. In: Kucharczyk J, Mosely M, Barkovich AJ (editors). Magnetic Resonance Neuroimaging. Boca Raton, FL: CRC Press; 1994. p. 245-318.

31. Badar-Goffer RS, Ben-Yoseph O, Bachelard HS, et al. Neuronal-glial metabolism under depolarizing conditions. Biochem J. 1992;282: 225-230.

32. Lee JH, Arcinue E, Ross BD. Organic osmolytes in the brain of an infant with hypernatremia. N Engl J Med. 1994;331:439-442.

33. Videen JS, Michaelis T, Pinto R, et al. Human cerebral osmolytes during chronic hyponatremia. A proton magnetic resonance spectroscopy study. J Clin Invest. 1995;95:788-793.

34. Castillo M, Kwock L, Scatliff JH, et al. Proton MR spectroscopic characteristics of a presumed giant subcortical heterotopia. AJNR Am J Neuroradiol. 1993;14:426-429.

35. Michaelis T, Merboldt KD, Bmhn H, et al. Absolute concentrations of metabolites in the adult human brain in vivo: Quantification of localized proton MR spectra. Radiology. 1993;187:219-227.

36. Hye A, Lynham S, Thambisetty M, et al. Proteome-based plasma biomarkers for Alzheimer's disease. Brain. 2006;129:3042-3050.

37. Frank RA, Galasko D, Hampel H, et al. Biological markers for therapeutic trials in Alzheimer's disease. Proceedings of the biological markers working group; NIA initiative on neuroimaging in Alzheimer's disease. Neurobiol Aging. 2003;24:521-536.

38. Consensus report of the Working Group on: "Molecular and Biochemical Markers of Alzheimer's Disease". The Ronald and Nancy Reagan Research Institute of the Alzheimer's Association and the National Institute on Aging Working Group. Neurobiol Aging. 1998;19:109-116.

39. Pratico D. Peripheral biomarkers of oxidative damage in Alzheimer's disease: the road ahead. Neurobiol Aging. 2005;26:581-583.

40. Solfrizzi V, D'Introno A, Colacicco AM, et al. Circulating biomarkers of cognitive decline and dementia. Clin Chim Acta. 2006;364:91-112.

41. Korolainen MA, Pirttila T. Cerebrospinal fluid, serum and plasma protein oxidation in Alzheimer's disease. Acta Neurol Scand. 2009;119: 32-38.

42. Lovell MA, Markesbery WR. Oxidative damage in mild cognitive impairment and early Alzheimer's disease. J Neurosci Res. 2007;85: 3036-3040.

43. Montine TJ, Quinn J, Kaye J, Morrow JD. F(2)-isoprostanes as biomarkers of late-onset al.zheimer's disease. J Mol Neurosci. 2007;33: $114-119$

44. Pratico D, Clark CM, Lee VM, Trojanowski JQ, Rokach J, FitzGerald GA. Increased 8,12-iso-iPF2alpha-VI in Alzheimer's disease: correlation of a noninvasive index of lipid peroxidation with disease severity Ann Neurol. 2000;48:809-812.

45. Quinn JF, Montine KS, Moore M, Morrow JD, Kaye JA, Montine TJ. Suppression of longitudinal increase in CSF F2-isoprostanes in Alzheimer's disease. J Alzheimers Dis. 2004;6:93-97.

46. Pratico D, Clark CM, Liun F, Rokach J, Lee VY, Trojanowski JQ. Increase of brain oxidative stress in mild cognitive impairment: a possible predictor of Alzheimer disease. Arch Neurol. 2002;59: 972-976.
47. Irizarry MC, Yao Y, Hyman BT, Growdon JH, Pratico D. Plasma F2A isoprostane levels in Alzheimer's and Parkinson's disease. Neurodegener Dis. 2007;4:403-405.

48. Akiyama H, Barger S, Barnum S, et al. Inflammation and Alzheimer's disease. Neurobiol Aging. 2000;21:383-421.

49. Yasojima K, Schwab C, McGeer EG, McGeer PL. Human neurons generate C-reactive protein and amyloid P: upregulation in Alzheimer's disease. Brain Res. 2000;887:80-89.

50. Engelhart MJ, Geerlings MI, Meijer J, et al; Inflammatory proteins in plasma and the risk of dementia: the Rotterdam study. Arch Neurol. 2004;61:668-672.

51. Schuitemaker A, Dik MG, Veerhuis R, et al. Inflammatory markers in $\mathrm{AD}$ and MCI patients with different biomarker profiles. Neurobiol Aging. 2009;30:1885-1889.

52. Veerhuis R, Van Breemen MJ, Hoozemans JM, et al. Amyloid beta plaque-associated proteins $\mathrm{C} 1 \mathrm{q}$ and SAP enhance the Abeta1-42 peptide-induced cytokine secretion by adult human microglia in vitro. Acta Neuropathol. 2003;105:135-144.

53. Dik MG, Jonker C, Hack CE, Smit JH, Comijs HC, Eikelenboom P. Serum inflammatory proteins and cognitive decline in older persons. Neurology. 2005;64:1371-1377.

54. Schmidt R, Schmidt H, Curb JD, Masaki K, White LR, Launer LJ; Early inflammation and dementia: a 25-year follow-up of the Honolulu-Asia Aging Study. Ann Neurol. 2002;52:168-174.

55. Yaffe K, Lindquist K, Penninx BW, et al. Inflammatory markers and cognition in well-functioning African-American and white elders. Neurology. 2003;61:76-80.

56. Ray S, Britschgi M, Herbert C, et al. Classification and prediction of clinical Alzheimer's diagnosis based on plasma signaling proteins. Nat Med. 2007;13:1359-1362.

57. Kaddurah-Daouk R, Soares JC, Quinones MP. Metabolomics: A global biochemical approach to the discovery of biomarkers for psychiatric disorders. New York, NY: Springer Science; 2009.

58. Raedler TJ, Wiedemann K. CSF-studies in neuropsychiatric disorders. Neuroendocrinol Lett. 2006;27:297-305.

59. Maier B, Laurer HL, Rose S, Buurman WA, Marzi I. Physiological levels of pro- and anti-inflammatory mediators in cerebrospinal fluid and plasma: a normative study. J Neurotrauma. 2005;22: 822-835.

60. Curzon G. Relationships between plasma, CSF and brain tryptophan. J Neural Transm Suppl. 1979;(15):81-92.

61. Obeid R, Kostopoulos P, Knapp JP, et al. Biomarkers of folate and vitamin B12 are related in blood and cerebrospinal fluid. Clin Chem. 2007;53:326-333.

62. Leoni V, Masterman T, Patel P, Meaney S, Diczfalusy U, Björkhem I. Side chain oxidized oxysterols in cerebrospinal fluid and the integrity of blood-brain and blood-cerebrospinal fluid barriers. J Lipid Res. 2003;44:793-799.

63. Levine J, Sela BA, Osher Y, et al. High homocycteine serum levels in young male schizophrenia and bipolar patients and animal model. Prog Neuropsychopharmacol Biol Psychiatr. 2005;29:1181-1191.

64. Rozen S, Cudkowicz ME, Bogdanov M, et al. Metabolomic analysis and signatures in motor neuron disease. Metabolomics. 2005;1:101-108.

65. Bogdanov M, Matson WR, Wang L, et al. Metabolomic profiling to develop blood biomarkers for Parkinson's disease. Brain. 2008;131: 389-396.

66. Underwood B, Broadhurst D, Dunn WB, et al. Huntington disease patients and transgenic mice have similar pro-catabolic serum metabolite profiles. Brain. 2006;129:877-886.

67. Tsang TM, Woodman B, McLoughlin GA, et al. Metabolic characterization of the R6/2 transgenic mouse model of Huntington's disease by high-resolution MAS 1H NMR spectroscopy. J Proteome Res. 2006;5:483-492.

68. Paige LA, Mitchell MW, Krishnan KR, Kaddurah-Daouk R, Steffens DC. A preliminary metabolomic analysis of older adults with and without depression. Int J Geriatr Psychiatry. 2007;22: 418-423. 
69. Kaddurah-Daouk R, McEvoy J, Baillie RA, et al. Metabolomic mapping of atypical antipsychotic effects in schizophrenia. Mol Psychiatry. 2007; 12:934-945.

70. James SJ, Melnyk S, Jernigan S, et al. Metabolic endophenotype and related genotypes are associated with oxidative stress in children with autism. Am J Med Genet B Neuropsych Genet. 2006;141B: 947-956.

71. Al-Gadani Y, Al-Ansary A, Al-Attas O, Al-Ayadhi L. Oxidative stress and antioxidant status in Saudi autistic children. Clin Biochem. 2009;42:1032-1040.

72. Marksteiner J, Kemmler G, Weiss EM, et al. Five out of 16 plasma signaling proteins are enhanced in plasma of patients with mild cognitive impairment and Alzheimer's disease. Neurobiol Aging. 2009;Apr 21 [Epub ahead of print].

73. Yoshidaa Y, Yoshikawab A, Kinumia T, et al. Hydroxyoctadecadienoic acid and oxidatively modified peroxiredoxins in the blood of Alzheimer's disease patients and their potential as biomarkers. Neurobiol Aging. 2009;30:174-185.

74. Al-Mosalem OA, Al-Ansary A, Attas O, Al-Ayadhi L. Metabolic biomarkers related to energy metabolism in Saudi autistic children. Clin Biochem. 2009;42:949-957.

75. Li L, Gao X, Zhao J, Ji X, Wei H, Luo Y. Plasma and cerebrospinal fluid substance $\mathrm{P}$ in post-stroke patients with depression. Psychiatry Clin Neurosci. 2009;63:298-304.

76. Sanyal J, Bandyopadhyay SK, Banerjee TK, et al. Plasma levels of lipid peroxides in patients with Parkinson's disease. Eur Rev Med Pharmacol Sci. 2009;13:129-132.

77. Scalzo PL, Ikuta N, Cardoso F, Regner A, Teixeira AL. Quantitative plasma DNA analysis in Parkinson's disease. Neurosci Lett. 2009; 452:5-7.

78. Chen CM, Liu JL, Wu YR, et al. Increased oxidative damage in peripheral blood correlates with severity of Parkinson's disease. Neurobiol Dis. 2009;33:429-435.

79. Buttarelli FR, Circella A, Pellicano C, et al. Dopamine transporter immunoreactivity in peripheral blood lymphocytes in multiple system atrophy. J Neural Transm. 2009;116:161-165.

80. Liu XQ, Liu XQ, Jiang P, Huang H, Yan Y. Plasma levels of endogenous hydrogen sulfide and homocysteine in patients with Alzheimer's disease and vascular dementia and the significance thereof. Zhonghua Yi Xue Za Zhi. 2008;88:2246-2249.

81. Zhang R, Miller RG, Gascon R, et al. Circulating endotoxin and systemic immune activation in sporadic amyotrophic lateral sclerosis (sALS). J Neuroimmunol. 2009;206:121-124.

82. Laske C, Stellos K, Stransky E, et al. Decreased plasma and cerebrospinal fluid levels of stem cell factor in patients with early Alzheimer's disease. J Alzheimers Dis. 2008;15:451-460.

83. Dong J, Robertson JD, Markesbery WR, Lovell MA. Serum zinc in the progression of Alzheimer's disease. J Alzheimers Dis. 2008;15: 443-450.

84. Porcellini E, Davis EJ, Chiappelli M, et al. Elevated plasma levels of alpha-1-anti-chymotrypsin in age-related cognitive decline and Alzheimer's disease: a potential therapeutic target. Curr Pharm Des. 2008;14:2659-2664.

85. De Felice C, Ciccoli L, Leoncini S, et al. Systemic oxidative stress in classic Rett syndrome. Free Radic Biol Med. 2009;47:440-448.

86. Heuer L, Ashwood P, Schauer J, et al. Reduced levels of immunoglobulin in children with autism correlates with behavioral symptoms. Autism Res. 2008;1:275-283.

87. James SJ, Rose S, Melnyk S, et al. Cellular and mitochondrial glutathione redox imbalance in lymphoblastoid cells derived from children with autism. FASEB J. 2009;23:2374-2383.

88. Dezortova M, Jiru F, Petrasek J, et al. $1 \mathrm{H}$ MR spectroscopy as a diagnostic tool for cerebral creatine deficiency. MAGMA. 2008;21: $327-332$.

89. Ashwood P, Kwong C, Hansen R, et al. Brief report: plasma leptin levels are elevated in autism: association with early onset phenotype? J Autism Dev Disord. 2008;38:169-175.
90. Boso M, Emanuele E, Politi P, et al. Reduced plasma apelin level in patient with autistic spectrum disorder. Arch Med Res. 2007;38: 70-74.

91. Vancassel S, Durand G, Barthélémy C, et al. Plasma fatty acid levels in autistic children. Prostaglandins Leukot Essent Fatty Acids. 2001; 65:1-7.

92. Sliwinski S, Croonenberghs J, Christophe A, Deboutte D, Maes M. Polyunsaturated fatty acids: do they have a role in the pathophysiology of autism? Neuro Endocrinol Lett. 2006;27: 465-471.

93. Strambi M, Longini M, Hayek J, et al. Magnesium profile in autism. Biol Trace Elem Res. 2006;109:97-104.

94. Dhossche D, Applegate H, Abraham A, et al. Elevated plasma gamma-aminobutyric acid (GABA) levels in autistic youngsters: stimulus for a GABA hypothesis of autism. Med Sci Monit. 2002;8: PR1-PR6.

95. Cohen BI. GABA-transaminase, the liver and infantile autism. Med Hypotheses. 2001;57:673-674.

96. Zavala M, Castejón HV, Ortega PA, Castejón OJ, Marcano de Hidalgo A, Montiel N. Imbalance of plasma amino acids in patients with autism and subjects with attention deficit/hyperactivity disorder. Rev Neurol. 2001;33:401-408.

97. Leventhal BL, Cook EH Jr, Morford M, Ravitz A, Freedman DX. Relationships of whole blood serotonin and plasma norepinephrine within families. J Autism Dev Disord. 1990;20:499-511.

98. Leboyer M, Philippe A, Bouvard M, et al. Whole blood serotonin and plasma beta-endorphin in autistic probands and their first-degree relatives. Biol Psychiatry. 1999;45:158-163.

99. Modahl C, Green L, Fein D, et al. Plasma oxytocin levels in autistic children. Biol Psychiatry. 1998;43:270-277.

100. Ernst M, Devi L, Silva RR, et al. Plasma beta-endorphin levels, naltrexone, and haloperidol in autistic children. Psychopharmacol Bull. 1993;29:221-227.

101. Eto I, Bandy MD, Butterworth CE Jr. Plasma and urinary levels of biopterin, neopterin, and related pterins and plasma levels of folate in infantile autism. J Autism Dev Disord. 1992;22: 295-308.

102. Wieand S, Gail MH, James BR, James KL. A family of nonparametric statistics for comparing diagnostic markers with paired or unpaired data. Biometrika. 1989;76:585-592.

103. Søreide K. Receiver-operating characteristic (ROC) curve analysis in diagnostic, prognostic and predictive biomarker research. J Clin Pathol. 2009;62:1-5.

104. Irizarry MC. Biomarkers of Alzheimer disease in plasma. NeuroRx. 2004;1:226-234.

105. Marksteiner J, Kemmler G, Weiss EM, et al. Five out of 16 plasma signaling proteins are enhanced in plasma of patients with mild cognitive impairment and Alzheimer's disease. Neurobiol Aging. 2009 Apr 21 [Epub ahead of print].

106. Allard L, Burkhard PR, Lescuyer P, et al. PARK7 and nucleoside diphosphate kinase A as plasma markers for the early diagnosis of stroke. Clin Chem. 2005;51:2043-2051.

107. Gerlach M, Hendrich A, Hueber R, et al. Potentielle biomarker der Parkinsonkrankheit. Aktuelle Neurologie Supplement. 2007;34: S28-S30.

108. Viant MR, Lyeth BG, Miller MG, Berman RF. An NMR metabolomic investigation of early metabolic disturbances following traumatic brain injury in a mammalian model. NMR Biomed. 2005;18: 507-516.

109. Holmes E, Tsang TM, Tabrizi SJ. The application of NMRbased metabonomics in neurological disorders. NeuroRx. 2006;3: $358-372$.

110. Dettmer K, Aronov PA, Hammock BD. Mass spectrometry-based metabolomics. Mass Spectrom Rev. 2007;26:51-78.

111. Dunn WB. Current trends and future requirements for the mass spectrometric investigation of microbial, mammalian and plant metabolomes. Phys Biol. 2008;5:1-24. 
112. Wikoff WR, Pendyala G, Siuzdak G, Fox HS. Metabolomic analysis of the cerebrospinal fluid reveals changes in phospholipase expression in the CNS of SIV-infected macaques. J Clin Invest. 2008;118: 2661-2669.

113. Soga T, Imaizumi M. Capillary electrophoresis method for the analysis of inorganic anions, organic acids, amino acids, nucleotides, carbohydrates and other anionic compounds. Electrophoresis. 2001;22: 3418-3425.
114. Dolník V, Dolníková J. Capillary zone electrophoresis of organic acids in serum of critically ill children. J Chromatogr A. 1995;716: 269-277.

Open Access Journal of Clinical Trials

\section{Publish your work in this journal}

The Open Access Journal of Clinical Trials is an international, peerreviewed, open access journal publishing original research, reports, editorials, reviews and commentaries on all aspects of clinical tria design, management, legal, ethical and regulatory issues, case record form design, data collection, quality assurance and data auditing methodologies. The manuscript management system is completely online and includes a very quick and fair peer-review system, which is all easy to use. Visit http://www.dovepress.com/testimonials.php to read real quotes from published authors.

Submit your manuscript here: http://www.dovepress.com/open-access-journal-of-clinical-trials-journal 